baber beftens empfohlen merben fann. Fei ber Serftellung ber Tier= bilber baben insbejondere bie treffliden photographijhen Pufnabmen in

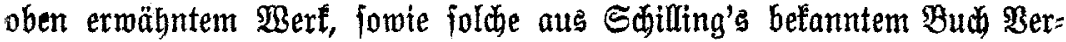
menbung gefunber.

\title{
IV. Alotizen.
}

\section{prüfung des Deutifhen forftwirtihaftsrates.}

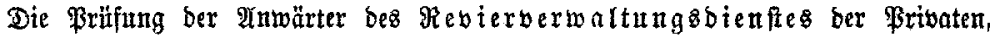
Gemeinber ufw., welde ber Dentfde Foritberein burd Mitglieber bes frorftwirtidafterates in zweijäbrigem Iurnu abhalten läß̄t, fanb in biefem Sabre im Monat September in Eijenad ftatt. Mro Brïfungalonmiffäre fungierten bie Serren Dberforftrat Eigner Megen\&burg, Dberforftrat Dr. Speibel= Stuttgart unb Forftrat Dr. Bertog=Berlin. Mngemerbet hatten ftof 29 Sanbibaten, yon benen auf (Grumb ber exfïften 3ulafiungs:

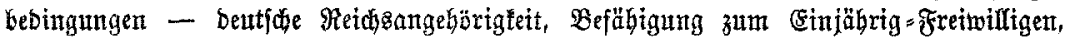

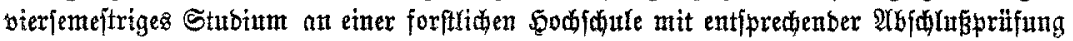

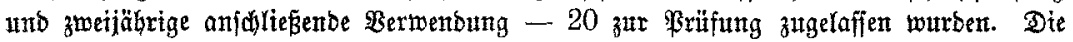

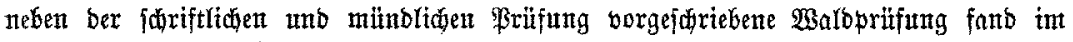

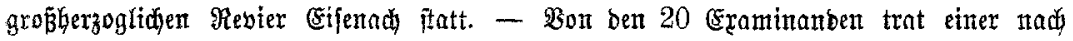

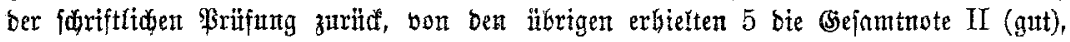
14 bie (Gejamtnote III (genitgent).

Die nädite Frïfung toiro im berbft 1915 abgehaltent.

\section{Die Befämpfung von Raucḩ̨ăden.}

Das $\mathfrak{A g l}$. Sädiffice Finanzminifterum gibt folgenbes befmut:

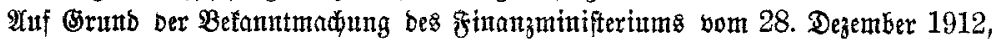
betreffenb bie Berbittung von Rauthidäben in ber Lanb= unb Fonftwittfiaft, finb eine

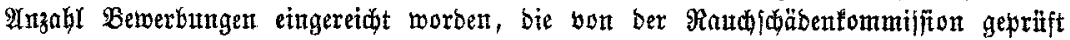

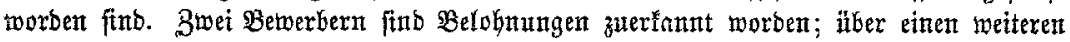
Boridlag find now erperimentelle Radizrïfungen im Snge.

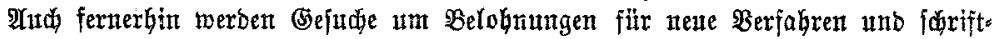

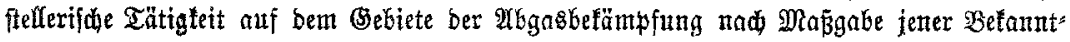
matung vom Finanzminifterium, II. 2rbteilung, entgegengentommen.

\section{Waldjamen Ernteberiht der firma heinrid Keller Sohn, Darmftadt.}

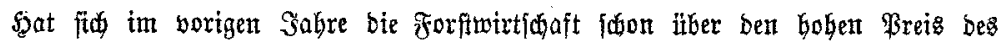

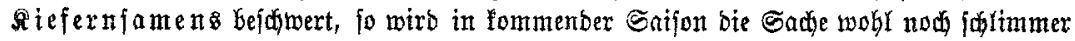
werben, wenigftens fili bie, bie nur Deutifien Samen faufen wollen. Die unter Rontrolle

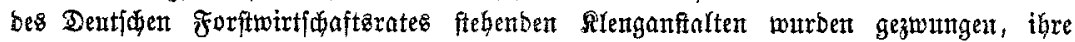

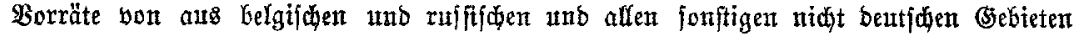

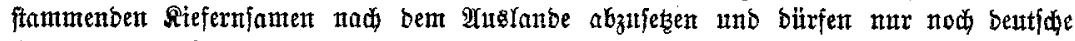
马apfen verarbeiten unb nur beatfien Samen verfautfen.

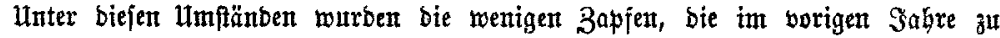
ernten waren, mit nod) nie bagewefentent Preifen bezabit. Die (sinte fommenben winter 